\title{
«Kleine Laboratoriumsexplosionen»
}

\author{
Erhard Taverna
}

Am 18. Juni 1909 schreibt Freud an Jung: «Kleine Laboratoriumsexplosionen werden bei der Natur des Stoffes, mit dem wir arbeiten, nie zu vermeiden sein. Man lernt so, was von der Gefahr am Stoff und was an der Handhabung liegt.» Der Ältere berät den Jüngeren in der heiklen Auseinandersetzung mit dessen Patientin und Geliebten Sabina Spielrein. Dank einem Dokumentenfund 1977 im Keller des Palais Wilson in Genf ist die Nachwelt im Besitze ihrer Korrespondenz mit Jung und Freud sowie ihres Tagebuches von 1909-1912. Über die «Affäre Spielrein» ist danach viel diskutiert und geschrieben worden, einmal weil Bettgeschichten berühmter Männer (Frauen?) grundsätzlich interessieren, weil heute die Folgen von Verführung und Missbrauch in einer Therapie besser erkannt sind und weil mit der Auswertung des Fundes die fällige Rehabilitation einer Forscherin und Analytikerin möglich wurde. Dokumente werden immer wieder neu gedeutet. Sabina Nikolajevna Spielrein (1885-1942), Kind eines jüdischen Kaufmanns aus Rostow am Don, war nacheinander ein psychiatrisch interessanter Fall, ein zu vertuschender Skandal, das Opfer einer kollegialen Verschwörung, die verleugnete Konkurrenz, von der schliesslich in der psychoanalytischen Literatur nur einige Fussnoten übrigblieben.

\section{Der Film}

Am Festival von Locarno kommentierte die Regisseurin Elisabeth Màrton ihren Dokumentarfilm «Ich hiess Sabina Spielrein», der im April 2002 erstmals in Düsseldorf an einem internationalen Symposium seine Uraufführung hatte. Sie habe während sieben Jahren recherchiert und gefilmt, stets auf Geldsuche und im Bestreben den Briefen und Tagebüchern eine lebendige Gestalt zurückzugeben. Die meist schwarzweiss gehaltene Doku-Fiktion reiht nahtlos Archivaufnahmen an gespielte Szenen und äussere Schauplätze aneinander, als wäre alles schon damals gedreht worden. Aus den Zitaten entsteht wie im Traum die innere und äussere Welt einer komplexen Beziehungsgeschichte. Die dichten Bilder lassen die Stationen von Sabina Spielrein wieder auferstehen, die Kamera folgt in Nahauf- nahmen der Schreibfeder, als würde das Tagebuch vor unseren Augen geschrieben. 1904/05 wird die erst 18jährige Patientin in der Klinik Burghölzli aufgenommen und von C. G. Jung, damals dreissig und verheiratet, behandelt. Mit Gesprächen nach der neuen Freudschen Methode behandelt, wird sie gesund und beginnt in Zürich das Studium der Medizin. Die damalige Diagnose ist heute umstritten: eine schwere Hysterie, eine Psychose oder die Lebenskrise einer sehr sensiblen und begabten Jüdin, für die es im zaristischen Russland keine Chancen gab. Sie dissertiert über einen Fall von Schizophrenie und entwickelt eine Theorie zur «Destruktion als Ursache des Werdens», die ebenfalls im renommierten «Jahrbuch der Psychiatrie» veröffentlicht wird. Sie wünscht sich nichts sehnlicher als ein Kind von Jung, der seine Liebesbeziehung $\mathrm{zu}$ ihr abrupt und in entwürdigender Weise abbricht. Hatte er sie eben noch als «Liebe Freundin» angesprochen, wird er sie bald nur noch Frau Doktor nennen. «Sie haben mein Unbewusstes mit Ihrem gepfefferten Brief tüchtig in die Finger genommen» schreibt er ihr vor dem ersten Rendezvous am Dampfschiffsteg Bahnhofstrasse. Später zitiert er Freud: «Je wertvoller ein Mensch ist - desto mehr kann er sublimieren.» In ihrer Not wenden sie sich beide an Freud, der sich allerdings auf die Seite seines Freundes stellt. Tapfer und hochbegabt schreibt sie die ersten kinderanalytischen Beiträge und gewinnt den Respekt von Freud, der ihr sogar Patienten schickt. Immer im Kontakt mit Jung heiratet sie in Rostow einen Arzt, arbeitet in Berlin, lebt in grosser Armut als alleinerziehende Mutter in Lausanne und findet Arbeit in Genf am weltbekannten Institut Rousseau. Sie hält Vorlesungen, publiziert und macht Lehranalysen mit Jean Piaget. Im Herbst 1923 wird sie wissenschaftliche Mitarbeiterin am staatlichen psychoanalytischen Institut in Moskau. Die noch junge Sowjetunion scheint eine grosse Zukunft $\mathrm{zu}$ ermöglichen, bis unter Stalin die Psychoanalyse verboten wird und die jüdische Intelligenz, wie Spielreins Brüder, im Gulag endet. Ein letzter Zeuge beobachtet wie die Vereinsamte mit ihren beiden Töchtern 1942 in Rostow von den Deutschen Besatzern ermordet wird. 


\section{Die Nachwelt}

1980 hat Aldo Carotenuto, Professor an der Universität Rom und Lehranalytiker, den in Genf entdeckten Nachlass geordnet und veröffentlicht. Die Rezeption der folgenden Jahrzehnte spiegelt auch ein Stück jüngste Zeitgeschichte, dessen Thema sich nicht nur auf das Schlagwort der «sexuellen Übergriffe in der Praxis» reduzieren lässt. Denn Spielrein war nicht nur Opfer, sie war, wie wir heute wissen, auch eine lange verkannte Forscherin. Der Film wird in seiner Darstellung nicht unbestritten bleiben, weil er eine einfache Schuldzuweisung vermeidet. Er betont die Tragik einer unerfüllten Liebe, die in den Pionierzeiten der Psychoanalyse auch zu Erkenntnissen, wie die der Gegenübertragung oder zu Freuds Forderung nach einer Eigenanalyse der Therapeuten beitrug. In einem der letzten Briefe gesteht ihr Jung, dass ihre Liebe in ihm etwas bewusst gemacht habe, das ihn «zu den allerwichtigsten Dingen führte». «Bisweilen muss man unwürdig sein, um überhaupt leben zu können», urteilt er über den weiteren Verlauf der Beziehung. Ihre konkreten wissenschaftlichen Beiträge erwähnt er nicht. Die «Laborexplosionen» haben Sabina Spielrein nicht umgebracht, aber lebenslänglich verletzt. Sie hat fast übermenschlich tapfer «sublimiert» und dabei unter schwierigsten Bedingungen Ausserordentliches geleistet.

\section{Literatur}

1 Màrton E (Regie). Ich hiess Sabina Spielrein. Stockholm: Produktion Idé Film Felixson AB; 2002.

2 Carotenuto A. Tagebuch einer heimlichen Symmetrie. Freiburg i. Br.: Verlag Traute Hensch; 1986. 